CLINICAL STUDY

\title{
Testosterone deficiency is associated with increased risk of mortality and testosterone replacement improves survival in men with type 2 diabetes
}

\author{
Vakkat Muraleedharan ${ }^{1,2}$, Hazel Marsh ${ }^{1}$, Dheeraj Kapoor ${ }^{1}$, Kevin S Channer ${ }^{3,4}$ and T Hugh Jones ${ }^{1,2}$ \\ ${ }^{1}$ Robert Hague Centre for Diabetes and Endocrinology, Barnsley Hospital NHSFT, Gawber Road, Barnsley S75 2EP, UK, ${ }^{2}$ Department of Human \\ Metabolism, The University of Sheffield, Beech Hill Road, Sheffield, UK, ${ }^{3}$ Department of Cardiology, Sheffield Teaching Hospital NHSFT, Royal Hallamshire \\ Hospital, Sheffield, UK and ${ }^{4}$ Department of Cardiovascular Medicine, Sheffield Hallam University, City Campus, Howard Street, Sheffield S1 1WB, UK \\ (Correspondence should be addressed to V Muraleedharan who is now at King's Mill Hospital, Sutton on Ashfield, Nottinghamshire NG17 4JL, UK; \\ Email: v.muraleedharan@nhs.net; T H Jones; Email: hugh.jones@nhs.net)
}

\begin{abstract}
Objective: Men with type 2 diabetes are known to have a high prevalence of testosterone deficiency. No long-term data are available regarding testosterone and mortality in men with type 2 diabetes or any effect of testosterone replacement therapy (TRT). We report a 6-year follow-up study to examine the effect of baseline testosterone and TRT on all-cause mortality in men with type 2 diabetes and low testosterone.

Research design and methods: A total of 581 men with type 2 diabetes who had testosterone levels performed between 2002 and 2005 were followed up for a mean period of $5.8 \pm 1.3$ s.D. years. Mortality rates were compared between total testosterone $>10.4 \mathrm{nmol} / \mathrm{l}(300 \mathrm{ng} / \mathrm{dl} ; n=343)$ and testosterone $\leq 10.4 \mathrm{nmol} / \mathrm{l}(n=238)$. The effect of TRT (as per normal clinical practise: $85.9 \%$ testosterone gel and $14.1 \%$ intramuscular testosterone undecanoate) was assessed retrospectively within the low testosterone group.

Results: Mortality was increased in the low testosterone group (17.2\%) compared with the normal testosterone group $(9 \% ; P=0.003)$ when controlled for covariates. In the Cox regression model, multivariate-adjusted hazard ratio (HR) for decreased survival was $2.02(P=0.009,95 \%$ CI 1.2-3.4). TRT (mean duration $41.6 \pm 20.7$ months; $n=64$ ) was associated with a reduced mortality of $8.4 \%$ compared with $19.2 \%(P=0.002)$ in the untreated group $(n=174)$. The multivariate-adjusted HR for decreased survival in the untreated group was 2.3 (95\% CI 1.3-3.9, $P=0.004)$.

Conclusions: Low testosterone levels predict an increase in all-cause mortality during long-term followup. Testosterone replacement may improve survival in hypogonadal men with type 2 diabetes.
\end{abstract}

European Journal of Endocrinology 169 725-733

\section{Introduction}

Several longitudinal population studies have reported that a low testosterone at baseline is associated with an increase in all-cause mortality (1). Some individual studies have specifically identified increases in cardiovascular, respiratory and cancer deaths $(2,3,4)$. A meta-analysis of published research papers with a mean follow-up period of 9.7 years confirmed that low testosterone was associated with increased risk of allcause and cardiovascular mortality in community based studies (1). Men with specific co-morbidities such as proven coronary artery disease and renal failure have also found that low testosterone predicts an increased risk of earlier death than those with the same condition and are testosterone replete $(5,6)$.

There is a high prevalence of low serum testosterone levels and clinical hypogonadism in men with type 2 diabetes $(7,8,9)$. Importantly, it has been established that both free testosterone (FT) assayed by equilibrium dialysis and bioavailable testosterone (free plus albumin-bound) assayed by ammonium sulphate precipitation are low in men with type 2 diabetes $(8,10,11)$. These findings demonstrate that low total testosterone (TT) cannot be fully accounted for by lower sex hormone binding globulin (SHBG) levels. Our previous study found a high prevalence of symptomatic hypogonadism in men with type 2 diabetes; $17 \%$ had TT $<8 \mathrm{nmol} / \mathrm{l}$ whereas a further $25 \%$ had testosterone levels between 8 and $12 \mathrm{nmol} / \mathrm{l}$ (8). Testosterone deficiency is known to have an adverse effect on several key cardiovascular risk factors which include central obesity, insulin resistance, hyperglycaemia, dyslipidaemia, inflammation and hypertension (12).

The major cause of death in men with type 2 diabetes is cardiovascular disease (CVD). Low testosterone has in 
several studies been linked with CVD (12). There is also evidence which has shown that the degree of atherosclerosis as assessed by the degree of carotid intimal media thickness (CIMT) is inversely associated with testosterone levels $(13,14,15)$. One study found that a low testosterone status was associated with greater progression of atherosclerosis as assessed by CIMT over a 4-year follow-up period (14). Furthermore, low testosterone is associated with a pro-inflammatory milieu and testosterone replacement suppresses circulating cytokines $(16,17)$.

Interventional trials have reported that testosterone replacement improves insulin resistance, glycaemic control, visceral obesity and lipid profile in the short term $(18,19,20,21,22,23)$. A large multi-centre, randomised, double-blind, placebo-controlled study was recently undertaken in eight European countries, the TIMES2 study, which showed that testosterone replacement therapy (TRT) improves certain cardiovascular risk factors which included insulin resistance, cholesterol, lipoprotein(a), body fat composition and sexual function in men with type 2 diabetes and/or the metabolic syndrome (21). There is no published data regarding mortality in men with type 2 diabetes and hypogonadism. Furthermore, it is not known if testosterone replacement has any effect on the longevity in these patients. We report a 6-year follow-up study of men with type 2 diabetes, looking at the impact of hypogonadism on mortality and the effect of testosterone replacement.

\section{Subjects and methods}

This was a prospective follow-up, using a cohort from a previously reported study on the prevalence of hypogonadism (8). The subjects involved in this study had been recruited from the district-wide diabetic retinopathy screening clinic, as well as the hospital diabetic clinic, and provided a representative sample from the general community. In addition, in this we also included all men with type 2 diabetes identified from the hospital database who had testosterone levels measured between October 2002 and December 2005 (during the same time period the original research cohort was recruited). All of these subjects were assessed and managed routinely within our diabetes clinic. The effect of TRT on mortality was based on a retrospective analysis of those subjects with hypogonadism who had been treated as part of normal clinical management compared with those who had not received treatment for reasons explained below. The study was approved by the South Yorkshire Research Ethics Committee.

Subjects were allocated to two groups based on the Endocrine Society Guidelines' (24) recommended cut-off level: i) TT levels $\leq 10.4 \mathrm{nmol} / \mathrm{l}$ and ii) TT $>10.4 \mathrm{nmol} / \mathrm{l}$. There were two different assays used for analysis of baseline TT. For those subjects from the hospital database, the assay was performed using a competitive chemiluminescent assay (Bayer Advia Centaur, Siemens Medical Solutions Diagnostics, Camberley, UK) and for those from the research database, a solid phase enzyme immunoassay (DRG Instruments $\mathrm{GmbH}$, Marburg, Germany) was used. Both assays are validated methods for assessing TT. A total of 36 patients from the research cohort had a repeat testosterone assay performed using the competitive chemiluminescent assay within a few months of the original screening. The results were comparable by the two methods with the difference between the means of the two groups not being statistically different $(0.33 \mathrm{nmol} / \mathrm{l}(95 \% \mathrm{CI}-1.22$ to 1.88; $P=0.669)$ ). All blood samples were taken between 0800 and $1100 \mathrm{~h}$. SHBG was measured by solid phase enzyme immunoassay (DRG Instruments $\mathrm{GmbH}$ ) for the research patients and by solid phase two-site chemiluminescent enzyme immunometric assay (Siemens Immulite, Siemens Medical Solutions Diagnostics) for the hospital clinic patients.

The effect of TRT on mortality was assessed retrospectively by including data from men who had received TRT for $>1$ year. Mean duration of TRT was $41.6 \pm 20.7$ months. A total of 60 patients received TRT for $>12$ months, 51 of these having treatment $>2$ years. All the patients who received TRT were initiated and monitored within our routine clinics in the diabetes and endocrinology department. Subjects from the original research cohort who had a low testosterone were invited to attend our clinic for further assessment as part of good clinical practise. For all patients who were already under our clinical care, as well as those who attended after invitation, were further assessed clinically for symptoms, repeat testosterone and gonadotropins measurement and other appropriate investigations. Patients were offered TRT if it was clinically indicated. The reasons for subjects not receiving TRT included patient choice, declined to attend for further clinical assessment, no response to clinic invitation, declined treatment after further analysis between 2002 and 2005. Generally, TRT was mainly given to men with testosterone levels below the local laboratory normal assay range $(<8.4 \mathrm{nmol} / \mathrm{l})$, without a concomitant diagnosis of prostate cancer or other contra-indications to TRT.

The majority of subjects who received TRT was initiated on a testosterone gel preparation (60/64), while three had buccal testosterone tablets and one intramuscular depot testosterone undecanoate (Nebido). The choice of initial therapy was based on the combined decision between the patient and doctor. Doses were adjusted to achieve testosterone levels within the mid to upper normal range. As a result of patient choice and/or side effects, preparations were changed in some individuals. In the TRT group, 55 patients $(85.9 \%)$ were stabilised on testosterone gel ( $1 \%$ testosterone gel Testogel/AndroGel or $2 \%$ testosterone gel via a metered pump; Tostran/Fortigel) and 
nine patients $(14.1 \%)$ on intramuscular testosterone undecanoate during the last 6 months or more of the study period.

The mean peak level achieved during the study period was $22.8( \pm 9.9) \mathrm{nmol} / \mathrm{l}: 43(67 \%)$ of the patients achieved a level of $>18 \mathrm{nmol} / \mathrm{l}$. Patient compliance was good as evidenced by the progressive improvement in the testosterone levels in most of the patients during the follow-up visits.

The causes of death were obtained from hospital records when available. For the remaining patients, death certificates were obtained from the local and national registries. Acute illness is known to cause a decrease in testosterone levels, so deaths which occurred in the first 6 months after baseline assessment were excluded.

Baseline data on age, height, weight, BMI, smoking, glycaemic control (HbA1c), angiotensin-converting enzyme inhibitor (ACEi) or angiotensin receptor blocker use (ARB), HMG CoA reductase inhibitor use (statins) and pre-existing CVDs for most of the patients were available from the research database. The remaining data were obtained from the hospital records. The baseline factors were then analysed for significance between two groups. These factors were then included in the covariate analysis using the Cox regression model.

SHBG results were available for 436 patients. Bioavailable testosterone (BT) and FT were calculated using validated mathematical formulae, the MorrisMalkin and Vermeulen equations respectively $(25,26)$.

After excluding deaths which occurred in the first 6 months $(n=4)$, data were then analysed using SPSS 15 Software with support from a University of Sheffield statistician. Kaplan-Meir curves were compared and significance was tested using the log rank method. Cox regression (forward conditional) model was used for multivariate survival analysis. Means (s.D.) hazard ratios (HR; 95\% CI) for survival and $P$ values for significance were calculated. Survival curves were plotted for ageand covariate-adjusted models with two groups of TT as categorical values (testosterone $\leq 10.4 \mathrm{nmol} / \mathrm{l}$ and
TT $>10.4 \mathrm{nmol} / \mathrm{l})$. Graphs were obtained using SPSS. For the analysis of the effect of testosterone replacement, after exclusion of the patients who were treated $<12$ months, the data were divided into three groups: 0 , low TT without treatment; 1, low TT with TRT; and 2, normal TT. The data were similarly analysed using Cox Regression model in SPSS.

\section{Results}

\section{Baseline characteristics}

A total of 591 patients with type 2 diabetes who had testosterone levels performed between the years 2002 and 2005 were identified from the databases. Baseline data is presented in Table 1 . We excluded deaths occurring in the first 6 months $(n=4)$ and those patients with a normal testosterone level at screening but subsequently developed hypogonadism and received treatment $(n=6)$. The remaining 581 subjects were followed up for a mean period of $5.8 \pm 1.7$ years. Mean age was 59.5 years ( \pm 10.8 ; range $31-88$ years). A total of $238(40.96 \%)$ had low TT $(\leq 10.4 \mathrm{nmol} / \mathrm{l})$ and $343(59.03 \%)$ with TT $>10.4 \mathrm{nmol} / \mathrm{l}$.

There were 353 patients from the research cohort and 228 patients from the hospital database who met the inclusion criteria and were included in the final analysis. The comparison between the two groups is shown in Table 2. The hospital database patients were older, more likely to have pre-existing CVD and statin treatment. The research cohort had more current smokers. There were no differences in weight, height, BMI, glycaemic control, ACE/ARB therapy, TT and SHBG levels between the groups.

The mean TT level was $15.7 \pm 4.5 \mathrm{nmol} / \mathrm{l}$ in the normal testosterone group as compared with $7.5 \pm 2 \mathrm{nmol} / \mathrm{l}$ in the low testosterone group $(P \leq 0.001)$. The weight $(102.1 \pm 21.4$ (low testosterone) vs $95.2 \pm 18.5 \mathrm{~kg}$ (normal testosterone), $P<0.001)$ and BMI $\left(33.6 \pm 6.1\right.$ vs $31.2 \pm 5.3 \mathrm{~kg} / \mathrm{m}^{2}$,

Table 1 Baseline characteristics.

\begin{tabular}{|c|c|c|c|c|c|}
\hline Variables & $\begin{array}{l}\text { Whole } \\
\text { population }\end{array}$ & $\begin{array}{l}\text { Patients with } \\
\text { missing values }^{c}\end{array}$ & $\begin{array}{c}\text { Normal testosterone } \\
\text { group }\end{array}$ & $\begin{array}{l}\text { Low testosterone } \\
\text { group }\end{array}$ & $\begin{array}{c}\text { Significance } \\
(P)\end{array}$ \\
\hline$n$ & 581 & & 343 & 238 & \\
\hline Testosterone levels $(\mathrm{nmol} / \mathrm{l})^{a}$ & $12.4(5.5)$ & 0 & $15.7(4.5)$ & $7.5(2)$ & $<0.001^{d}$ \\
\hline Age (years) ${ }^{a}$ & $59.5(10.8)$ & 0 & $58.9(10.4)$ & $60.3(11.5)$ & $0.15^{\mathrm{d}}$ \\
\hline SHBG levels $(\mathrm{nmol} / \mathrm{l})^{a}$ & $32.2(19.7)$ & $144(24.8)$ & 36.7 (20.8) & $25.8(16.2)$ & $<0.001^{d}$ \\
\hline $\mathrm{HbA} 1 c^{\mathrm{a}}$ & $7.3(1.4)$ & $8(1.4 \%)$ & $7.2(1.4)$ & $7.5(1.3)$ & $0.002^{d}$ \\
\hline Height $(\mathrm{cm})^{\mathrm{a}}$ & $174.3(6.8)$ & $74(12.7 \%)$ & $174.3(6.8)$ & $174.3(6.8)$ & $0.94^{d}$ \\
\hline $\mathrm{BMI}^{\mathrm{a}}$ & $32.4(5.8)$ & $89(15.3 \%)$ & $31.3(5.3)$ & $33.6(6.1)$ & $<0.001^{d}$ \\
\hline Statin therapy ${ }^{\mathrm{b}}$ & $260(48.1 \%)$ & $40(6.9 \%)$ & $161(50 \%)$ & $99(45 \%)$ & $0.29^{e}$ \\
\hline Current smokers ${ }^{b}$ & $104(9.3 \%)$ & $43(7.4 \%)$ & $67(20.9 \%)$ & $37(17 \%)$ & $0.089^{e}$ \\
\hline ACEI/ARB therapy ${ }^{b}$ & $260(48.1 \%)$ & $30(5.2 \%)$ & $183(56 \%)$ & $125(55.8 \%)$ & $1^{\mathrm{e}}$ \\
\hline Pre-existing CVD ${ }^{\mathrm{b}}$ & $213(39.2 \%)$ & $38(6.5 \%)$ & $120(37.2 \%)$ & $93(42.3 \%)$ & $0.25^{\mathrm{e}}$ \\
\hline
\end{tabular}

${ }^{a}$ Mean with s.D.; ${ }^{b}$ number with percentage within the groups; ${ }^{c}$ numbers of patients with percentage of the total; ${ }^{d}$ analysis by $t$-test; ${ }^{e}$ by $\chi^{2}$. 
Table 2 Comparison between Hospital and Research Cohorts.

\begin{tabular}{|c|c|c|c|}
\hline Variables & $\begin{array}{l}\text { Hospital } \\
\text { patients }\end{array}$ & $\begin{array}{l}\text { Research } \\
\text { patients }\end{array}$ & $\begin{array}{c}\text { Significance } \\
(P)\end{array}$ \\
\hline$n$ & 228 & 353 & \\
\hline $\begin{array}{l}\text { Testosterone levels } \\
(\mathrm{nmol} / \mathrm{l})^{\mathrm{a}}\end{array}$ & $11.9 \pm 5.3$ & $12.7 \pm 5.6$ & $0.079^{c}$ \\
\hline Age (years) ${ }^{a}$ & $62 \pm 11.3$ & $58 \pm 10.2$ & $<0.001^{\mathrm{c}}$ \\
\hline SHBG levels $(\mathrm{nmol} / \mathrm{l})^{\mathrm{a}}$ & $31.2 \pm 18.9$ & $32.4 \pm 20$ & $0.584^{\mathrm{c}}$ \\
\hline $\mathrm{HbA} 1 c^{\mathrm{a}}$ & $7.4+1.5$ & $7.2+1.3$ & $0.096^{c}$ \\
\hline Weight $(\mathrm{kg})^{\mathrm{a}}$ & $97.1 \pm 19.8$ & $98.4 \pm 20.1$ & $0.482^{c}$ \\
\hline Height $(\mathrm{cm})^{\mathrm{a}}$ & $174.7 \pm 6.8$ & $174.1 \pm 6.7$ & $0.356^{\mathrm{c}}$ \\
\hline$B M l^{\mathrm{a}}$ & $31.7 \pm 5.5$ & $32.4 \pm 5.9$ & $0.243^{\mathrm{c}}$ \\
\hline Statin therapy ${ }^{\mathrm{b}}$ & $112(59.3 \%)$ & $169(47.9 \%)$ & $0.012^{d}$ \\
\hline Current smokers ${ }^{\mathrm{b}}$ & $35(18.8 \%)$ & $69(19.5 \%)$ & $0.017^{d}$ \\
\hline ACEl/ARB therapy ${ }^{b}$ & $112(56.6 \%)$ & $196(55.5 \%)$ & $0.585^{d}$ \\
\hline Pre-existing CVD & $97(49.7 \%)$ & $117(33.3 \%)$ & $<0.001^{d}$ \\
\hline
\end{tabular}

${ }^{a}$ Mean with s.D.; ${ }^{b}$ number with percentage within the groups; ${ }^{c}$ analysis by $t$-test; ${ }^{d}$ by $\chi^{2}$.

$P<0.001)$ were higher in the low testosterone group and they were more likely to have poorer diabetes control than the normal testosterone group (HbA1c, $7.5 \pm 1.3$ vs $7.2 \pm 1.4 ; P=0.002)$. Both groups were matched for age, smoking status, pre-existing CVD, statin and ACE inhibitors or ARB therapy.

\section{Mortality}

There were 72 deaths after the initial 6-month period. Individual causes of deaths were 34 cardiovascular deaths (which included coronary artery disease, cerebrovascular disease, peripheral vascular disease and pulmonary embolism), 13 respiratory disease deaths, 17 cancer deaths and eight other causes which included gastrointestinal haemorrhage (3), renal failure (1), sepsis (3) and suicide (1). Mean baseline testosterone levels were significantly low in patients who died $(10.9 \pm 5.2$ S.D. $)$ when compared with those who are alive $(12.6 \pm 5.5 ; P=0.018)$. The mortality rate was $17.2 \%(41 / 238)$ in the low testosterone group compared with $9 \%(31 / 343, P=0.003)$ in the normal testosterone group.

The Kaplan-Meier survival curves showed a significant decrease in survival in the low testosterone group compared with the normal testosterone group $(P=0.002 \log$ rank $)$. In the Cox regression model (forward conditional) after adjusting for covariates (age, pre-existing CVD, weight, height, BMI, HbA1c, smoking, statin and ARB/ACEi therapy) at baseline, the HR for decreased survival was $2.02(P=0.009,95 \%$ CI 1.2-3.4; Fig. 1).

The survival curves demonstrated evidence of divergence after 12 months of follow-up. Apart from testosterone other factors which significantly affected survival were age (HR 1.07; 95\% CI 1.05-1.11; $P<0.001)$, pre-existing CVD $(2.1 ; 95 \%$ CI 1.2-3.6; $P=0.008)$ and $\mathrm{HbAlc}(1.3 ; 95 \%$ CI 1.1-1.4;
$P=0.008)$. There were 17 cardiovascular deaths in each group. There were no significant differences between the two groups in cardiovascular and cancer mortality. However, at a sub-analysis using a TT cut-off level below the normal assay range of $8.4 \mathrm{nmol} / \mathrm{l}$, there was a significant increase in cardiovascular mortality in low testosterone patients when compared with those above $8.4 \mathrm{nmol} / \mathrm{l}$ with a multivariate-adjusted HR 2.5 $(P=0.021,95 \%$ CI 1.2-5.38).

The higher mortality persisted after adjusting for SHBG (HR 2.2; 95\% CI 1.2-4; $P=0.008$ ). However, when age adjustment was performed along with SHBG, the significance in mortality was lost but approached significance $(P=0.064)$. These results suggest an influence of age-related SHBG change on the mortality outcome. SHBG was not measured at baseline in all patients $(437 / 581)$. When the hospital and research cohorts were analysed separately, the mortality difference persisted in the hospital cohort. However, there was a non-significant difference in the research cohort possibly due to a relatively small number of events in that group.

Further analysis using BT with a cut-off level of $\leq 2.6 \mathrm{nmol} / \mathrm{l}$ (below the normal range) demonstrated survival curves similar to those found with TT (2.4; 95\% CI 1.3-4.6; $P=0.006$; Fig. 2). However, there was no significant difference in mortality found with FT $<225 \mathrm{pmol} / \mathrm{l}$ with those above this cut-off level $(P=0.19)$.

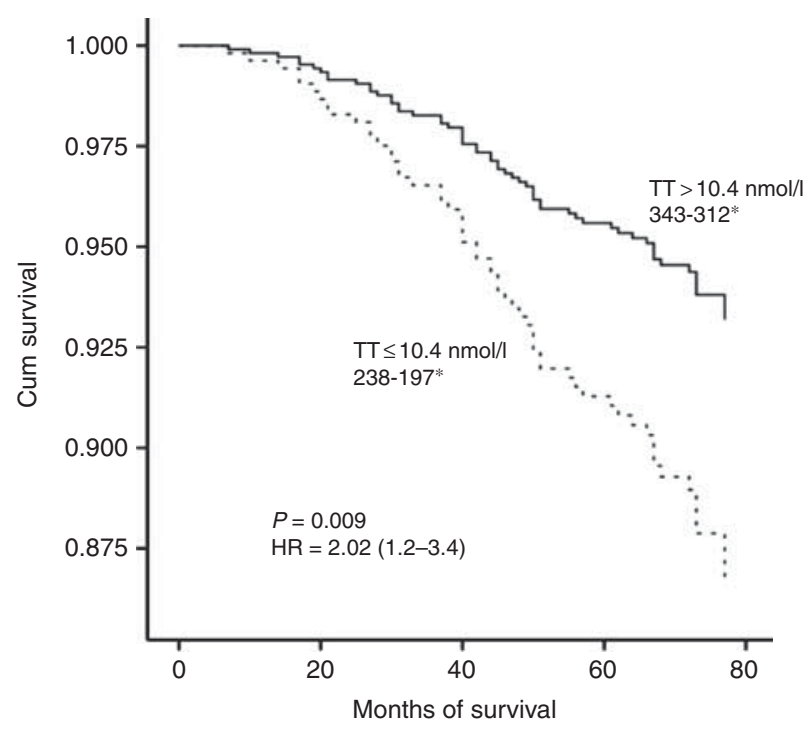

Figure 1 Multivariate-adjusted survival curves using Cox regression model for all-cause mortality based on total testosterone (TT). The solid line represents male subjects with a baseline TT $>10.4 \mathrm{nmol} / \mathrm{I}$ and the broken line represents TT $\leq 10.4 \mathrm{nmol} / \mathrm{l}$. HR, hazard ratio for decreased survival after adjusting for $\mathrm{BMI}, \mathrm{HbA1c}$, pre-existing cardiovascular disease, smoking, statin and ACEI/ARB therapy. *The number of patients alive at the start of the study and at the end of the study. 


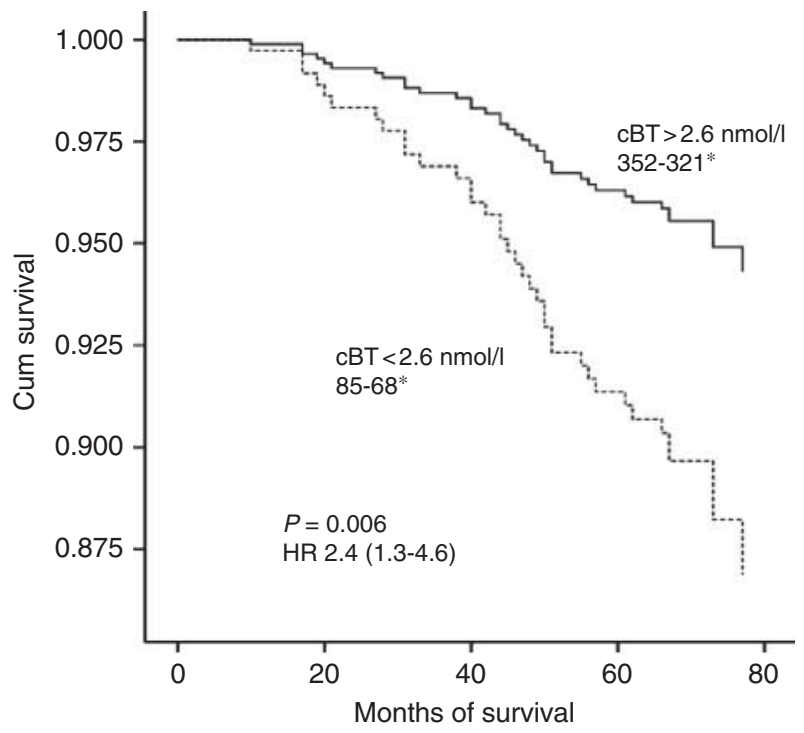

Figure 2 Multivariate-adjusted survival curves using Cox regression model for all-cause mortality based on calculated bioavailable testosterone (cBT). The solid line represents male subjects with a baseline $\mathrm{CBT}>2.6 \mathrm{nmol} / \mathrm{l}$ and the broken line represents $\mathrm{CBT}$ $\leq 2.6 \mathrm{nmol} / \mathrm{l}$. HR, hazard ratio for decreased survival after adjusting for $\mathrm{BMI}, \mathrm{HbA1c}$, pre-existing cardiovascular disease, smoking, statin and ACEI/ARB therapy. ${ }^{*}$ The number of patients alive at the start of the study and at the end of the study of a total of 437 patients analysed.

\section{Effect of TRT}

Three groups were analysed to assess the effect of TRT on mortality. The low TT group was further divided in to those who received TRT, the treated group, and those who did not, the untreated group. Of the 238 men with low testosterone, 64 patients $(27 \%)$ received TRT and 174 did not. Mean duration of TRT was $41.6 \pm 20.7$ (s.D.) months. A total of 60 patients received TRT for 12 months or more and 51 had treatment for 2 years or more. The normal TT group remained the same as no subjects received TRT. The groups were equally matched for age, weight, height, BMI, HbAlc, preexisting CVD, smoking status, statin, and ACEi and ARB therapy (Table 3).

There was a significant increase in mortality rate $(20.11 \%(35 / 174))$ in the untreated group, in comparison with $9.38 \%(6 / 64)$ in the treated group $(P=0.002)$ and $9.12 \%(31 / 340)$ in the normal group. KaplanMeier curves showed a significant decrease in survival in the untreated when compared with treated and normal groups (log rank 0.001). In the Cox regression model, multivariate analysis was performed including the covariates of age, weight, height, BMI, HbAlc, preexisting CVD, smoking status, statin, and ACEi and ARB treatment. The HR for decreased survival in the untreated group was 2.3 ; 95\% CI 1.3-3.9; $P=0.004$. The survival curve for the treated group followed a similar course to that of the normal population (Fig. 3).
Interestingly, in this analysis the difference in mortality persisted after adjustment for SHBG along with age. This may be due to the change in SHBG with TRT which might have an effect on long-term survival. However, as we do not have the data for SHBG after TRT this cannot be verified.

\section{Discussion}

This longitudinal cohort study is the first study in men with type 2 diabetes which demonstrates that testosterone status at baseline predicts a significant increase in risk of subsequent mortality in men with type 2 diabetes during long-term follow-up. Importantly, the increase in mortality was found to be independent of age, glycaemic control, BMI, pre-existing CVD, current smoking status and treatment with either statins, ACEI or ARB at baseline. Other factors which predicted increased mortality in this analysis were age, baseline HbAlc and pre-existing CVD. HbAlc and BMI were significantly higher in the low testosterone group. The major single cause of mortality in the study was CVD with acute coronary artery disease accounting for the majority of cases. No significant increase in CV mortality in the low testosterone group was identified. However, a sub-analysis of men with TT less than the normal range did detect an increased risk of $\mathrm{CV}$ mortality compared with those with levels within the normal range. There was also a trend towards an increase respiratory disease mortality in the low testosterone group, but the significance was lost when adjusted for covariates. This might be explained by the relatively small number of respiratory-related deaths in the cohort.

Although several population studies have reported an association of increased mortality with low testosterone, the effect of TRT has not been studied. When we reviewed those patients who received TRT for 1 year or longer, we found a beneficial effect improving survival in

Table 3 Baseline data for the treated and untreated groups.

\begin{tabular}{|c|c|c|c|c|}
\hline Variables & Untreated & Treated & $\begin{array}{c}\text { Patients } \\
\text { with miss- } \\
\text { ing values }^{c}\end{array}$ & $\begin{array}{c}\text { Signifi- } \\
\text { cance } \\
(P)\end{array}$ \\
\hline$n$ & 174 & 64 & & \\
\hline $\begin{array}{l}\text { Testosterone } \\
\text { levels }(\mathrm{nmol} / \mathrm{l})^{\mathrm{a}}\end{array}$ & $7.8(1.9)$ & $6.8(2.3)$ & 0 & $0.003^{d}$ \\
\hline Age (years) ${ }^{a}$ & $60.9(11.8)$ & 58.5 (S.D.) & 0 & $0.16^{\mathrm{d}}$ \\
\hline Weight $(\mathrm{kg})^{\mathrm{a}}$ & $100.8(21.8) 1$ & $105.4(20.1)$ & $30(12.9 \%)$ & $0.14^{d}$ \\
\hline Height $(\mathrm{cm})^{\mathrm{a}}$ & $174.3(7.2) \quad 1$ & $174.5(5.5)$ & $29(12.5 \%)$ & $0.99^{\mathrm{d}}$ \\
\hline $\mathrm{BMI}^{\mathrm{a}}$ & $33.3(6.3)$ & $34.3(5.5)$ & $37(15.9 \%)$ & $0.31^{d}$ \\
\hline $\mathrm{HbA} 1 c^{\mathrm{a}}$ & $7.4(1.3)$ & $7.7(1.3)$ & $4(1.7 \%)$ & $0.21^{d}$ \\
\hline Statin therapy ${ }^{b}$ & $87(54.4 \%)$ & $33(56 \%)$ & $18(7.6 \%)$ & $0.88^{e}$ \\
\hline ACE/ARB therapy ${ }^{b}$ & $89(54.6 \%)$ & $36(59 \%)$ & $14(5.9 \%)$ & $0.65^{e}$ \\
\hline Current smokers ${ }^{b}$ & $27(16.8 \%)$ & $10(17.2 \%)$ & $17(7.3 \%)$ & $0.39^{e}$ \\
\hline Pre-existing CVD ${ }^{\mathrm{b}}$ & $71(44.3 \%)$ & $22(36.7 \%)$ & 19 (8\%) & $0.34^{\mathrm{e}}$ \\
\hline
\end{tabular}

${ }^{a}$ Mean with S.D.; ${ }^{b}$ number with percentage within the groups; ${ }^{c}$ numbers with percentage of the total; ${ }^{d}$ analysis by $t$-test; ${ }^{\mathrm{e}}$ by $\chi^{2}$. 


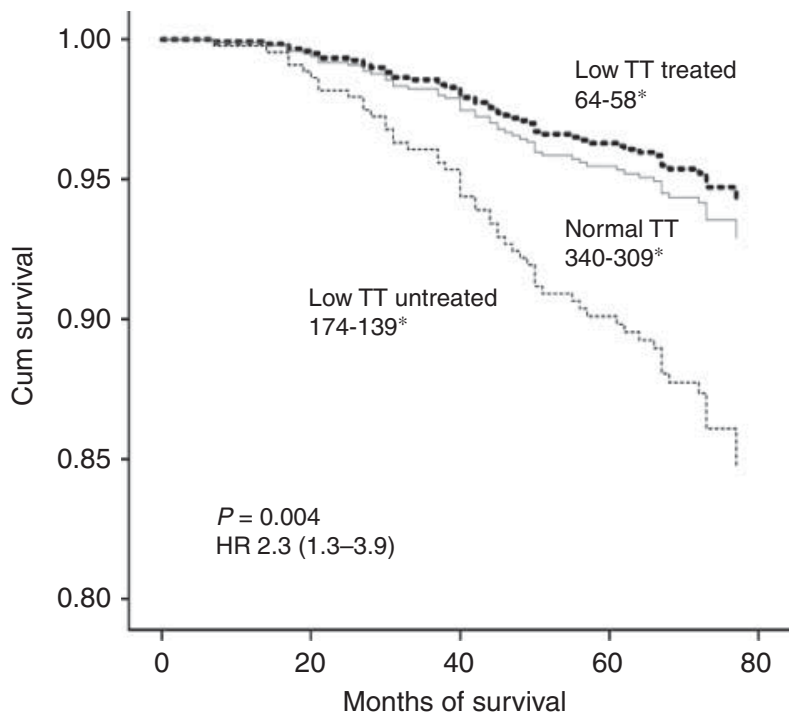

Figure 3 Multivariate-adjusted survival curves using Cox regression model for treated and untreated groups compared with those with normal testosterone. The lighter broken line represents male subjects with total testosterone (TT) levels $<10.4 \mathrm{nmol} / \mathrm{l}$ without treatment, the continuous line represent those with TT levels $>10.4 \mathrm{nmol} / \mathrm{l}$ and the darker broken line represent those with TT levels $<10.4 \mathrm{nmol} / \mathrm{l}$ and who received physiological testosterone replacement. HR, hazard ratio for decreased survival after adjusting for BMI, HbA1c, pre-existing cardiovascular disease, smoking, statin and ACEI/ARB therapy. ${ }^{*}$ The number of patients alive at the start of the study and at the end of the study.

men with hypogonadism. The data showed that the survival curve followed a similar course to that of the normal testosterone group, whereas the untreated group had a worse prognosis. It is important to note that all patients treated with testosterone had careful adjustment of testosterone to achieve levels within the mid to upper normal range for healthy men. This is the first time any study on men with type 2 diabetes has shown that TRT may improve long-term survival outcome. This is especially important in men with type 2 diabetes who have a considerably reduced life expectancy.

A recently reported study involving 1031 male veterans over the age of 40 years showed that in men with low testosterone levels, TRT was associated with a decrease in mortality as compared with those who were not treated (27). This study compared survival in treated vs untreated men with hypogonadism with a mortality of $10.3 \%$ in the treated group and $20.7 \%$ in the untreated group. We found a similar rate of mortality in our study with $9.1 \%$ in the treated group compared with $20.1 \%$ in those who were not treated. Our study differed from that of veterans, in which we had the advantage of a control group of testosteronereplete men albeit with type 2 diabetes. In addition, our study included only men with type 2 diabetes, whereas the veterans study was a general population with either none or mixed co-morbidities (38\% diabetes, 36\% sexual dysfunction and 21 coronary heart disease). Nevertheless there are now two studies which are in general agreement that TRT improves survival in hypogonadal men.

It is appreciated that a limitation of this study in regard to the effect of TRT is that the data were collected retrospectively and that the patients were not randomised for treatment. In addition, those patients treated were clinically more overtly hypogonadal with symptoms and lower testosterone levels (mean baseline testosterone untreated, $7.8 \pm 1.9$ vs $6.8 \pm 2.3 \mathrm{nmol} / \mathrm{l}$ treated; $P=0.003$ ) resulting in a treatment bias. However, the fact that the HR for mortality deteriorates when the treated patients (which include those with lower testosterone) are excluded suggests that this is not the case. We appreciate that it is important to recognise that these findings do need to be confirmed in an appropriately designed prospective placebo-controlled trial. However, the findings presented here are the first to suggest a favourable outcome of TRT specifically on survival in hypogonadal men with type 2 diabetes.

There were two groups of patients in the cohort: one screened for hypogonadism as part of research and the rest were identified from hospital laboratory records (all subjects had been assessed in our diabetes clinic) and the case notes were used to obtain the baseline data at the time of screening. The cause of death from hospital records and the national registry may not always reflect the exact cause of death. However, a large cohort makes this less likely to be a confounding factor. We did not find any significant difference between numbers of preexisting CVD in the two groups, and deaths in the first 6 months were excluded from analysis. This is especially important because we have previously reported that low testosterone is a risk factor for mortality in men with proven coronary artery disease (5). The numbers of events in the whole groups were small and we are unable to predict the median survival in the Cox regression model.

Evidence is accumulating that a low testosterone is a risk factor for reduced survival particularly in relation to CVD. This evidence is supported by long-term follow-up studies in men treated for prostate cancer with androgen deprivation therapy (ADT) compared with those who were treated conservatively $(28,29)$. The majority but not all studies found an increase in CVD, myocardial infarction, incident diabetes, life-threatening arrhythmias and sudden cardiovascular death. Changes in key cardiovascular risk factors can be adversely affected within 3 months of initiation of ADT (29). A science advisory from the American Heart Association, American Cancer Society and the American Urological Association has recommended that all patients receiving ADT should have periodic follow-ups for the assessment of cardiovascular risk factors and those with coexisting CVD should have their treatment for secondary prevention optimised (29). 
It is a common and generally accepted perception that low testosterone levels are a biomarker of ill health which occurs as a result of increased circulating cytokines in chronic diseases suppressing the hypothalamic-pituitary-gonadal axis. However, the role of testosterone deficiency in accelerating disease progression and equally that of replacing testosterone is not fully understood. As previously described, evidence suggests that testosterone deficiency promotes an increase in CIMT, a surrogate marker of in vivo atherosclerosis (14). Our study and the veterans study (27), both suggest that testosterone substitution in hypogonadal men improves mortality outcome.

TRT has been used to treat male hypogonadism since the late 1930s. Preparations of testosterone administration have improved over the last 15 years to allow testosterone replacement to within the normal physiological range. All patients in this study were treated by dose titration in the clinic to achieve serum levels in the mid to upper normal range. Several metaanalyses of trials of TRT have not found any increase in adverse cardiovascular events in hypogonadal men (30, 31, 32, 33). Furthermore, higher endogenous testosterone levels are not associated with cardiovascular events (33). One study which reported an increase in cardiovascular-related symptoms or events used twice the standard routine clinical initiation dose in frail elderly men with a high number of co-morbidities (34). A similar study using standard testosterone dose replacement did not report any increase in cardiovascular events (35). Testosterone replacement to normal testosterone levels has been used in a number of studies involving men with significant cardiac disorders including chronic stable angina and moderate chronic cardiac failure for up to 12 months with no evidence of adverse effects importantly including mortality $(36,37$, $38,39)$. The improvement in survival in this type 2 diabetes population supports the evidence that testosterone has a beneficial effect on health. However, it is recognised that until a long-term randomised placebocontrolled trial reports results, a definitive answer cannot be given.

In summary, this is the first study to demonstrate that low testosterone levels are associated with an increase in all-cause and cardiovascular mortality in men with type 2 diabetes. This study demonstrates that long-term testosterone replacement is not only safe in terms of mortality but may also improve survival in men with type 2 diabetes and hypogonadism. Further studies are needed to confirm these data. Our clinical practise is to replace testosterone to levels within the normal healthy range with careful monitoring of testosterone levels with adjustment of dose and safety (haematocrit, PSA) and this would appear to be a sensible and safe approach to clinical management. These findings are also in line with the beneficial effects of TRT on the cardiovascular risk factors in men with low testosterone that include insulin resistance, central obesity and cholesterol lowering and also suggest that these might be translated into long-term survival benefits (40).

\section{Declaration of interest}

V Muraleedharan was part supported by Bayer Healthcare UK. T H Jones has received research grants from Bayer Healthcare UK and received honoraria for advisory boards and educational lectures from Bayer Healthcare, Clarus, Lilly, Merck and Prostrakan. K S Channer has received honoraria for advisory boards and educational lectures from Bayer Healthcare and Prostrakan. H Marsh and D Kapoor have no conflicts.

\section{Funding}

V Muraleedharan is supported by Bayer Schering Pharma and funded by Barnsley Hospital NHSFT, Bayer Healthcare and Barnsley Hospital Endocrinology Research Fund.

\section{Author contribution statement}

$\mathrm{V}$ Muraleedharan researched the data and wrote the manuscript. D Kapoor contributed to research. H Marsh contributed to research and discussion. K S Channer contributed to research and review of manuscript. T H Jones conceived and designed the study, contributed to research, reviewed and edited the manuscript. T H Jones is the guarantor of this work and had full access to all of the data in the study and takes responsibility for the integrity of the data and accuracy of data analysis.

\section{References}

1 Araujo AB, Dixon JM, Suarez EA, Murad MH, Guey LT \& Wittert GA. Endogenous testosterone and mortality in men: a systematic review and meta-analysis. Journal of Clinical Endocrinology and Metabolism 201196 3007-3019. (doi:10.1210/jc. 2011-1137)

2 Khaw K-T, Dowsett M, Folkerd E, Bingham S, Wareham N, Luben R, Welch A \& Day N. Endogenous testosterone and mortality due to all causes, cardiovascular disease, and cancer in men: European Prospective Investigation Into Cancer in Norfolk (EPIC-Norfolk) Prospective Population Study. Circulation 2007116 2694-2701. (doi:10.1161/CIRCULATIONAHA.107.719005)

3 Laughlin GA, Barrett-Connor E \& Bergstrom J. Low serum testosterone and mortality in older men. Journal of Clinical Endocrinology and Metabolism 200893 68-75. (doi:10.1210/jc. 2007-1792)

4 Ponikowska B, Jankowska EA, Maj J, WegrzynowskaTeodorczyk K, Biel B, Reczuch K, Borodulin-Nadzieja L, Banasiak W \& Ponikowski P. Gonadal and adrenal androgen deficiencies as independent predictors of increased cardiovascular mortality in men with type II diabetes mellitus and stable coronary artery disease. International Journal of Cardiology 2010143 343-348. (doi:10.1016/j.ijcard.2009.03.072)

5 Malkin CJ, Pugh PJ, Morris PD, Asif S, Jones TH \& Channer KS. Low serum testosterone and increased mortality in men with coronary heart disease. Heart 201096 1821-1825. (doi:10.1136/hrt. 2010.195412)

6 Carrero JJ, Qureshi AR, Parini P, Arver S, Lindholm B, Bárány P, Heimbürger O \& Stenvinkel P. Low serum testosterone increases mortality risk among male dialysis patients. Journal of the American Society of Nephrology 200920 620. (doi:10.1681/ASN. 2008060664)

7 Ding EL, Song Y, Malik VS \& Liu S. Sex differences of endogenous sex hormones and risk of type 2 diabetes: a systematic review and meta-analysis [Review]. Journal of the American Medical Association 2006295 1288-1299. (doi:10.1001/jama.295.11.1288) 
8 Kapoor D, Aldred H, Clark S, Channer KS \& Jones TH. Clinical and biochemical assessment of hypogonadism in men with type 2 diabetes: correlations with bioavailable testosterone and visceral adiposity. Diabetes Care 200730 911-917. (doi:10.2337/dc06-1426)

9 Wang C, Jackson G, Jones TH, Matsumoto AM, Nehra A, Perelman MA, Swerdloff RS, Traish A, Zitzmann M \& Cunningham G. Low testosterone associated with obesity and the metabolic syndrome contributes to sexual dysfunction and cardiovascular disease risk in men with type 2 diabetes. Diabetes Care 201134 1669-1675. (doi:10.2337/dc10-2339)

10 Barrett-Connor E \& Khaw KT. Endogenous sex hormones and cardiovascular disease in men. A prospective population-based study. Circulation 198878 539-545. (doi:10.1161/01.CIR.78.3.539)

11 Dhindsa S, Prabhakar S, Sethi M, Bandyopadhyay A, Chaudhuri A \& Dandona P. Frequent occurrence of hypogonadotropic hypogonadism in type 2 diabetes. Journal of Clinical Endocrinology and Metabolism 2004 89 5462-5468. (doi:10.1210/jc.2004-0804)

12 Jones TH. Testosterone deficiency: a risk factor for cardiovascular disease? Trends in Endocrinology and Metabolism 201021496 503. (doi:10.1016/j.tem.2010.03.002)

13 Fukui M, Kitagawa Y, Nakamura N, Kadono M, Mogami S, Hirata C, Ichio N, Wada K, Hasegawa G \& Yoshikawa T. Association between serum testosterone concentration and carotid atherosclerosis in men with type 2 diabetes. Diabetes Care 200326 1869-1873. (doi:10.2337/diacare.26.6.1869)

14 Muller M, van den Beld AW, Bots ML, Grobbee DE, Lamberts SW \& van der Schouw YT. Endogenous sex hormones and progression of carotid atherosclerosis in elderly men. Circulation 2004109 2074-2079. (doi:10.1161/01.CIR.0000125854.51637.06)

15 Svartberg J, Von Muhlen D, Mathiesen E, Joakimsen O, Bonaa KH \& Stensland-Bugge E. Low testosterone levels are associated with carotid atherosclerosis in men. Journal of Internal Medicine 2006 259 576-582. (doi:10.1111/j.1365-2796.2006.01637.x)

16 Kapoor D, Clarke S, Stanworth R, Channer KS \& Jones TH. The effect of testosterone replacement therapy on adipocytokines and C-reactive protein in hypogonadal men with type 2 diabetes. European Journal of Endocrinology 2007156 595-602. (doi:10. 1530/EJE-06-0737)

17 Nettleship JE, Pugh PJ, Channer KS, Jones T \& Jones RD. Inverse relationship between serum levels of interleukin-1 $\beta$ and testosterone in men with stable coronary artery disease. Hormone and Metabolic Research 200739 366-371. (doi:10.1055/s-2007976543)

18 Kalinchenko SY, Tishova YA, Mskhalaya GJ, Gooren LJG, Giltay EJ \& Saad F. Effects of testosterone supplementation on markers of the metabolic syndrome and inflammation in hypogonadal men with the metabolic syndrome: the double-blinded placebo-controlled Moscow study (vol 73, pg 602, 2010). Clinical Endocrinology 2011 75 275. (doi:10.1111/j.1365-2265.2011.04105.x)

19 Kapoor D, Goodwin E, Channer KS \& Jones TH. Testosterone replacement therapy improves insulin resistance, glycaemic control, visceral adiposity and hypercholesterolaemia in hypogonadal men with type 2 diabetes. European Journal of Endocrinology 2006154 899-906. (doi:10.1530/eje.1.02166)

20 Heufelder AE, Saad F, Bunck MC \& Gooren L. Fifty-two-week treatment with diet and exercise plus transdermal testosterone reverses the metabolic syndrome and improves glycemic control in men with newly diagnosed type 2 diabetes and subnormal plasma testosterone. Journal of Andrology 200930 726-733. (doi:10. 2164/jandrol.108.007005)

21 Jones TH, Arver S, Behre HM, Buvat J, Meuleman E, Moncada I, Morales AM, Volterrani M, Yellowlees A, Howell JD et al. Testosterone replacement in hypogonadal men with type 2 diabetes and/or metabolic syndrome (the TIMES2 Study). Diabetes Care 201134 828-837. (doi:10.2337/dc10-1233)

22 Agarwal PK \& Oefelein MG. Testosterone replacement therapy after primary treatment for prostate cancer. Journal of Urology 2005173 533-536. (doi:10.1097/01.ju.0000143942. $55896.64)$

23 Malkin CJ, Pugh PJ, Jones RD, Kapoor D, Channer KS \& Jones TH. The effect of testosterone replacement on endogenous inflammatory cytokines and lipid profiles in hypogonadal men. Journal of Clinical Endocrinology and Metabolism 200489 33133318. (doi:10.1210/jc.2003-031069)

24 Bhasin S, Cunningham GR, Hayes FJ, Matsumoto AM, Snyder PJ, Swerdloff RS \& Montori VM. Testosterone therapy in men with androgen deficiency syndromes: an Endocrine Society clinical practice guideline. Journal of Clinical Endocrinology and Metabolism 201095 2536-2559. (doi:10.1210/jc.2009-2354)

25 Morris PD, Malkin CJ, Channer KS \& Jones TH. A mathematical comparison of techniques to predict biologically available testosterone in a cohort of 1072 men. European Journal of Endocrinology 2004151 241-249. (doi:10.1530/eje.0.1510241)

26 Vermeulen A, Verdonck L \& Kaufman JM. A critical evaluation of simple methods for the estimation of free testosterone in serum. Journal of Clinical Endocrinology and Metabolism $1999 \mathbf{8 4}$ 3666-3672. (doi:10.1210/jc.84.10.3666)

27 Shores MM, Smith NL, Forsberg CW, Anawalt BD \& Matsumoto AM. Testosterone treatment and mortality in men with low testosterone levels. Journal of Clinical Endocrinology and Metabolism 201297 2050-2058. (doi:10.1210/jc.2011-2591)

28 Keating NL, O'Malley AJ \& Smith MR. Diabetes and cardiovascular disease during androgen deprivation therapy for prostate cancer [Report]. Journal of Clinical Oncology $2006 \mathbf{2 4} 4448-4456$. (doi:10.1200/JCO.2006.06.2497)

29 Levine GN, D’Amico AV, Berger P, Clark PE, Eckel RH, Keating NL, Milani RV, Sagalowsky AI, Smith MR, Zakai N et al. Androgendeprivation therapy in prostate cancer and cardiovascular risk. A science advisory From the American Heart Association, American Cancer Society, and American Urological Association Endorsed by the American Society for Radiation Oncology. Circulation 2010 121 833-840. (doi:10.1161/CIRCULATIONAHA.109.192695)

30 Calof OM, Singh AB, Lee ML, Kenny AM, Urban RJ, Tenover JL \& Bhasin S. Adverse events associated with testosterone replacement in middle-aged and older men: a meta-analysis of randomized, placebo-controlled trials. Journals of Gerontology. Series A, Biological Sciences and Medical Sciences 200560 1451-1457. (doi:10.1093/ gerona/60.11.1451)

31 Haddad RM, Kennedy CC, Caples SM, Tracz MJ, Bolona ER, Sideras K, Uraga MV, Erwin PJ \& Montori VM. Testosterone and cardiovascular risk in men: a systematic review and meta-analysis of randomized placebo-controlled trials. Mayo Clinic Proceedings 200782 29-39. (doi:10.4065/82.1.29)

32 Merce Fernandez-Balsells M, Murad MH, Lane M, Lampropulos JF, Albuquerque F, Mullan RJ, Agrwal N, Elamin MB, GallegosOrozco JF, Wang AT et al. Adverse effects of testosterone therapy in adult men: a systematic review and meta-analysis. Journal of Clinical Endocrinology and Metabolism 201095 2560-2575. (doi:10.1210/jc.2009-2575)

33 Carson CC III \& Rosano G. Exogenous testosterone, cardiovascular events, and cardiovascular risk factors in elderly men: a review of trial data. Journal of Sexual Medicine 20129 54-67. (doi:10.1111/ j.1743-6109.2011.02337.x)

34 Basaria S, Coviello AD, Travison TG, Storer TW, Farwell WR, Jette AM, Eder R, Tennstedt S, Ulloor J, Zhang AQ et al. Adverse events associated with testosterone administration. New England Journal of Medicine $2010363 \quad 109-122 . \quad$ (doi:10.1056/ NEJMoa1000485)

35 Srinivas-Shankar U, Roberts SA, Connolly MJ, Connell MD, Adams JE, Oldham JA \& Wu FC. Effects of testosterone on muscle strength, physical function, body composition, and quality of life in intermediate-frail and frail elderly men: a randomized, doubleblind, placebo-controlled study. Journal of Clinical Endocrinology and Metabolism 201095 639-650. (doi:10.1210/jc.2009-1251)

36 English KM, Steeds RP, Jones TH, Diver MJ \& Channer KS. Lowdose transdermal testosterone therapy improves angina threshold in men with chronic stable angina - a randomized, double-blind, placebo-controlled study. Circulation 2000102 1906-1911. (doi:10.1161/01.CIR.102.16.1906)

37 Mathur A, Malkin C, Saeed B, Muthusamy R, Jones TH \& Channer K. Long-term benefits of testosterone replacement 
therapy on angina threshold and atheroma in men. European Journal of Endocrinology 2009161 443-449. (doi:10.1530/EJE09-0092)

38 Malkin CJ, Pugh PJ, West JN, van Beek EJ, Jones TH \& Channer KS. Testosterone therapy in men with moderate severity heart failure: a double-blind randomized placebo controlled trial. European Heart Journal 200627 57-64. (doi:10.1093/eurheartj/ehi443)

39 Caminiti G, Volterrani M, Iellamo F, Marazzi G, Massaro R, Miceli M, Mammi C, Piepoli M, Fini M \& Rosano GM. Effect of long-acting testosterone treatment on functional exercise capacity, skeletal muscle performance, insulin resistance, and baroreflex sensitivity in elderly patients with chronic heart failure a double-blind, placebo-controlled, randomized study. Journal of the American College of Cardiology 200954 919-927. (doi:10. 1016/j.jacc.2009.04.078)

40 Rao PM, Kelly DM \& Jones TH. Testosterone and insulin resistance in the metabolic syndrome and T2DM in men. Nature Reviews. Endocrinology 20139 479-493. (doi:10.1038/nrendo.2013.122)

Received 16 April 2013

Revised version received 30 July 2013

Accepted 29 August 2013 